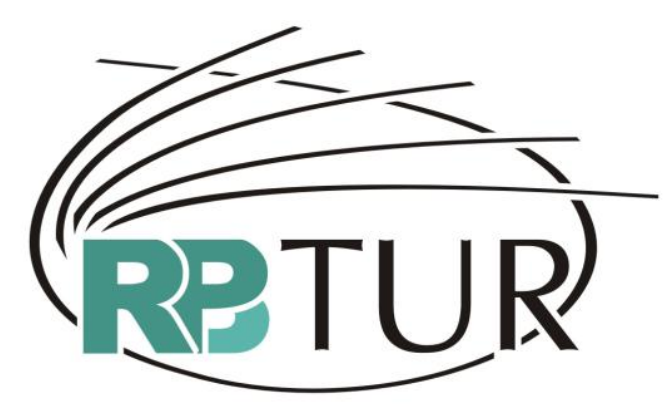

REVISTA BRASILEIRA DE PESQUISA EM TURISMO

\title{
UM OLHAR SOBRE OS DISCURSOS ACADÊMICOS E MIDIÁTICOS DO AGROTURISMO EM SANTA ROSA DE LIMA/SC ${ }^{1}$
}

\author{
UNA MIRADA SOBRE LOS DISCURSOS ACADÉMICOS E \\ MEDIÁTICOS SOBRE AGROTURISMO EN SANTA ROSA DE \\ LIMA, ESTADO DE SANTA CATARINA, BRASIL
}

\begin{abstract}
A GLIMPSE OF ACADEMIC AND MEDIA DISCOURSES OF AGRITOURISM IN SANTA ROSA DE LIMA-SC (STATE OF SANTA CATARINA, BRAZIL)
\end{abstract}

\author{
Yolanda Flores e Silva² \\ Felipe Borborema Cunha Lima ${ }^{3}$ \\ Luana de Souza Oliveira ${ }^{4}$
}

\begin{abstract}
Resumo: O presente trabalho apresenta uma discussão sobre o turismo comunitário em área rural enquanto atividade que transforma e modifica pessoas e ambientes, visto ser antes de tudo uma área que permeia contextos e vidas nas mais distintas dimensões do viver humano. Analisamos esta realidade a partir das interseções e diferenças entre os discursos produzidos em duas pesquisas realizadas nos últimos dois anos. Cada uma, a partir de um olhar distinto (pesquisa 1 - discurso acadêmico / pesquisa 2 - discursos midiáticos) sobre o mesmo fenômeno, apresenta eixos diferenciados de avaliação sobre as percepções que os sujeitos podem construir de uma mesma situação. Para a elaboração desse texto traçamos os seguintes percursos
\end{abstract}

${ }^{1}$ Trabalho apresentado no VI Seminário da Associação Brasileira de Pesquisa e Pós-graduação em Turismo - ANPTUR 2009.

2 Docente e pesquisadora da Universidade do Vale do Itajaí (UNIVALI)/Centro de Ciências Sociais Aplicadas: Comunicação, Turismo e Lazer - Programa de Pós-graduação stricto sensu em Turismo e Hotelaria - Mestrado Acadêmico. Email: yolanda@univali.br

${ }^{3}$ Bacharel em Turismo pelo Centro de Ensino Superior e Desenvolvimento. Mestre em Turismo e Hotelaria pela Universidade do Vale do Itajaí (UNIVALI). Consultor da ONG Araucária (SC) e pesquisador do Núcleo de Pesquisa Turismo Espaço e Sociedade do Mestrado em Turismo e Hotelaria da UNIVALI. Email: felipebcl2@hotmail.com

${ }^{4}$ Bacharel em Turismo pela Universidade Federal do Pará. Mestre em Turismo e Hotelaria pela Universidade do Vale do Itajaí (UNIVALI). Professora do Instituto Federal do Tocantins. Email: oliveiras.luana@gmail.com 
metodológicos: leitura dos resultados de cada pesquisa, seleção dos discursos considerando as categorias de análise convergentes e divergentes e por fim a análise conjunta dos dados e a discussão dos mesmos. Ao final percebemos a existência de dois discursos, com um formato ou uma imagem do turismo desvirtuada do fenômeno em análise e, portanto capaz de criar expectativas ou desestímulo desnecessário e até prejudicial às propostas futuras de crescimento da atividade turística na região.

Palavras-chave: Turismo. Agroturismo. Discursos. Santa Rosa de Lima. Santa Catarina. Brasil.

Abstract: This paper presents a discussion of tourism in rural areas, as an activity that transforms and changes people and environments, as it is primarily a field that permeates the lives and contexts over different dimensions of human living. We analyze this situation from the intersections and differences between the discourses produced in two surveys conducted in the last two years. Each one, from a distinct look (Research 1 - academic discourse / research 2 - media discourses) about the same phenomenon presents different evaluation axes about the perceptions that individuals can build in the same situation. For the preparation of this text we draw the following methodological paths: reading the results of each survey, selection of speeches given the categories of convergent and divergent analysis, and finally the joint analysis of data and discussion of them. At the end we realize the existence in the two speeches, a format or a distorted image tourism phenomenon in question and therefore able to raise expectations or discourage unnecessary and even harmful to the proposed future growth of tourism in the region.

Keywords: Tourism. Agritourism. Discourses. Santa Rosa de Lima. Santa Catarina. Brazil.

Resumen: En este trabajo se discute el turismo comunitario en áreas rurales como actividad que transforma y modifica personas y ambientes, ya que se trata de una área que atraviesa el contexto y las vidas en sus más diversas dimensiones. Analizamos esta realidad a partir de las intersecciones y diferencias entre los discursos producidos en dos investigaciones realizadas en los últimos dos años. Cada una, a partir de una mirada distinta (la primera desde el discurso académico y la segunda desde los discursos mediáticos) sobre el mismo fenómeno, presente ejes diferentes de evaluación de las percepciones que los sujetos tienen de una misma situación. Para la elaboración de este artículo se dieron los siguientes pasos metodológicos: lectura de los resultados de cada investigación, selección de los discursos considerando las categorías de análisis convergentes y divergentes y finalmente el análisis conjunto de los datos y la discusión de los mismos. Notamos la existencia de dos discursos, con un formato o una imagen desvirtuada del turismo, capaces o de crear expectativas desnecesarias o de desalentar otras, lo que puede ser igualmente perjudicial a las propuestas futuras de crecimiento de la actividad turística en la región.

Palabras clave: Turismo. Agriturismo. Discursos. Santa Rosa de Lima. Santa Catarina, Brasil.

\section{Considerações Iniciais}

Este artigo é resultado da união de duas pesquisas realizadas a partir de um projeto-base, desenvolvido há mais de 10 anos em uma comunidade rural 
do Estado de Santa Catarina por alunos do Mestrado Acadêmico em Turismo e Hotelaria da Universidade do Vale do Itajaí (UNIVALI). O corpus das duas pesquisas foi o modelo agroturístico do município de Santa Rosa de Lima, com 'sujeitos' diferentes. Oliveira (2009) centrou-se nos 'sujeitos' discursivos presentes em discursos acadêmicos e Cunha Lima (2009) nos 'sujeitos' formadores das matérias jornalísticas sobre o agroturismo e seus resultados nas Encostas da Serra Geral Catarinense.

Considerando o universo de semelhanças e diferenças entre estes dois discursos, elaboramos uma análise acerca da inter-relação dos discursos midiáticos e acadêmicos. Para tanto, traçamos o seguinte percurso metodológico:

1) Leitura dos resultados de cada dissertação;

2) Seleção dos discursos considerando categorias de análise comuns e diferenças;

3) Análise conjunta dos dados e discussão dos mesmos. Importante ressaltar que cada dissertação fez seu próprio percurso de coleta e análise do mesmo fenômeno, contudo utilizando modelos de análise dos discursos que permitiam a reflexão sobre os construtores dos discursos e dos possíveis leitores dos mesmos.

Na dissertação de Oliveira (2009) foram identificados e analisados doze (12) estudos científicos [sete (07) artigos e cinco (05) dissertações], produzidos entre 2002 e 2007 com o objeto de analisar o agroturismo de SANTA ROSA DE LIMA. A identificação destes estudos foi realizada através de uma coleta intencional em bancos de dados eletrônicos de quarenta e uma (41) unidades de ensino superior (universidades e centros universitários privados e públicos) da região sul. Os trabalhos selecionados são a síntese de diversos outros trabalhos identificados, entretanto, apenas os doze trabalhos selecionados atendiam aos critérios estabelecidos na proposta da investigação realizada: dissertações, artigos e capítulos de livros elaborados em mestrados em Turismo ou de outras áreas, mas com enfoque no turismo. As universidades que serviram de base para as dissertações selecionadas foram a 
Universidade Federal de Santa Catarina (UFSC) e a Universidade do Vale do Itajaí (UNIVALI). Os artigos foram identificados em periódicos nacionais, anais de eventos científicos e capítulo de livro. Para análise desse material usamos a técnica do "Discurso do Sujeito Coletivo" de Levéfre e Lefévre (2003), adaptado para material impresso.

O corpus da pesquisa de Cunha Lima (2009) compreendeu a seleção de noventa (90) matérias de caráter jornalístico, publicadas no período entre 2004 e 2008 sobre a atividade do agroturismo de SANTA ROSA DE LIMA e municípios que aderiram à proposta nos últimos dez anos principalmente. Para a confirmação de algumas informações ou a melhor definição de determinados conteúdos das matérias, entrevistamos seis (06) pessoas envolvidas no processo de organização, suporte, promoção e desenvolvimento dos projetos relacionados ao agroturismo na região. Após a identificação e seleção destes materiais, a caracterização e análise foram realizadas através de uma estratégia de análise de discurso denominada de "Modelo de Cooperação Textual" de Eco (1986) adaptado por Silva (1999).

\section{Mídia e Ciência na Construção da Realidade Através da Informação e do Conhecimento}

Mesmo que a mídia e a academia façam parte de mundos diferentes, ambas produzem informações que influenciam direta ou indiretamente a sociedade. A mídia funciona como um processador de imagens, textos e sons, que inibe e intensifica os desejos e as necessidades da população, estimulando a formação de novos padrões culturais. Por outro lado a academia dá um caráter científico ao conhecimento empírico e pode colaborar para a solução dos problemas da comunidade ao compartilhar com esta os resultados de suas pesquisas.

Mesmo existindo diferenças de conteúdo e foco entre os assuntos veiculados pela mídia e pela academia ambas podem gerar conhecimentos e ou informações que causam transformações sociais. Para Montiel (2003) a 
informação em si constitui-se em dados contextualizados e dirigidos a um receptor e se caracteriza pela não neutralidade e sujeita a interpretações. Ainda segundo Montiel (2003), o conhecimento é uma noção complexa que nasce da reflexão e do processamento de informações que refletem dados e experiências individuais, como no caso das representações, crenças e práticas compartilhadas por pessoas que fazem parte do mesmo grupo cultural.

O processo de socialização, ao longo de nossa vida, interioriza-se em nós, interferindo diretamente nas questões culturais e comportamentais relacionadas aos nossos gostos, escolhas, modo de pensar, crenças, valores. Esses aprendizados estão presentes em cada pessoa, influenciando seu modo de agir, pensar e sentir, e é essa construção subjetiva das ações aprendidas socialmente que nos leva ao fato-social (SANTOS, 2005).

Considerando e reconhecendo que vivemos experiências muito distintas entre nós, porque esta é percebida por cada um segundo a sua própria construção de vida, entendemos então que esta forma de concepção é que nos faz perceber e construir discursos diferentes ainda que estejamos a expressálo a partir de um mesmo fenômeno. Nesse sentido, podemos afirmar também que o discurso é dotado de sentido a partir de um extradiscurso, sendo necessária à relação entre os contextos social, econômico e político em que se dá o discurso, operando a linguagem como meio de representação. Os meios de comunicação assumem o "papel de mecanismo de constituição dos universos simbólicos, [...] elemento indispensável no processo de identificação, apreensão e compreensão das relações sociais pelos indivíduos" (GADINI, 1999, p. 12). Assim o jornalismo assume o papel de fragmento da realidade, fruto de um jogo de fatores e códigos de produção discursiva, e veicula o discurso resultante da colagem de vozes e sentidos, gerando uma compreensão singular do cotidiano.

Processo semelhante também ocorre com as produções cientificas que são diferenciadas pelo modo como são divulgadas. Para Bauer (1997) a socialização do conhecimento pode ocorrer em duas direções: uma descendente, quando o saber científico é popularizado, e outra ascendente, 
quando o senso comum é cientificado. Pensando nos canais ascendentes como divulgadores da ciência, é possível inferir que estes estimulam o pensamento teórico. Por sua vez, os canais descendentes voltam-se mais para o estímulo do pensamento mítico com a formação de imagens e de símbolos.

O sistema simbólico, como instrumento de conhecimento e de comunicação, possui um caráter estruturante, e por isso apresenta um poder de construção da realidade que tende a estabelecer uma ordem, um sentido imediato do mundo, em particular do mundo social. Os símbolos são os instrumentos de conhecimento e de comunicação que tornam possível o consenso acerca do sentido do mundo social e contribui fundamentalmente para a reprodução da ordem social (BOURDIEU, 2002).

Uma vez que o comportamento das pessoas é um reflexo da sociedade, evidencia-se nessa dinâmica do viver cotidiano que "os indivíduos adaptam instantaneamente seus comportamentos às cenas sociais das quais participam" (BEAUD; WEBER, 2007, p.216). Novos símbolos levam a novos vínculos identificatórios e conseqüentemente a novos papéis. As pessoas passam a apresentar papéis e identidades diluídas, influenciadas por distintas manifestações culturais de natureza lingüística e/ou étnica, por exemplo (MONTIEL, 2003).

A construção dos papéis é que leva a institucionalização da conduta, uma vez que é através desses que as instituições incorporam-se à experiência de cada homem/mulher. Mesmo existindo diferentes maneiras de como concebemos o mundo, a análise dos papéis revela as mediações existentes entre os universos macroscópicos de significação, objetivados por nossas sociedades e os modelos pelos quais estes universos são subjetivamente reais para as pessoas. Nesse caminho está o pensamento de Berger e Luckmann (1985, p.103) quando afirmam que "ao desempenhar papéis, o individuo participa de um mundo social. Ao interiorizar estes papéis, o mesmo mundo torna-se real para ele".

Nas duas pesquisas realizadas, observamos a descrição de mundos, pessoas e papéis com discursos e interpretações opostas entre si, mostrando 
as alteridades dos olhares particulares de pesquisadores e jornalistas com suas subjetividades mediadas por suas crenças acerca do modo de vida e trabalho dos atores sociais envolvidos.

\section{O Município Investigado}

O município de Santa Rosa de Lima localiza-se no sul de Santa Catarina, distante 120 quilômetros da capital Florianópolis. A atividade turística é uma conseqüência das transformações que vem ocorrendo nos últimos dez anos, com a implantação do modelo agroeocológico que surgiu fundamentado no associativismo e cooperativismo, despertando em pesquisadores e técnicos de distintas áreas o interesse em conhecer o município. Essa demanda de pessoas para conhecer o que se fazia na região fez com que os agricultores percebessem no turismo um novo nicho de oportunidades. Em 1999 é fundada então a Associação de Agroturismo Acolhida na Colônia (AAAC) que tem em sua filosofia de atuação os princípios de desenvolvimento sustentável. Para fazer parte dessa associação, os agricultores e suas famílias devem seguir o estatuto e o caderno de normas para implantação de plantações orgânicas com práticas éticas e sustentáveis. Dentre as ações previstas pela AAAC, estão a preservação das matas nativas, proteção das fontes e o tratamento dos esgotos, aliado ao desenvolvimento da atividade turística como segunda alternativa (FEUSER, 2006).

O movimento agroturístico, assim como o agroecológico em função das ações que vêm desenvolvendo, é responsável por inúmeras mudanças em Santa Rosa de Lima e municípios vizinhos. As mudanças são de natureza física, com a pavimentação de ruas, revitalização de espaços públicos e construção de espaços para restauração e hospedagem; comportamentais, com a aquisição de novos papéis e novos hábitos sociais, educacionais, alimentares e corporais; interacionais com a criação de entidades associativas como a Cooperativa dos Profissionais (ALIAR) e a Associação de Desenvolvimento das Encostas da Serra Geral para Alimentação e 
Hospedagem, que têm como objetivo gerenciar esta nova realidade. Até a conclusão das pesquisas aqui analisadas Santa Rosa de Lima oferecia hospedagem com alimentação em cinco pousadas coloniais e em duas residências, assim como atividades de descanso, relaxamento e contemplação através de passeios em trilhas, pescas em açudes, rafting, trekking, banhos em águas termais [Balneário Paraíso das Águas - o novo parceiro não associado da $A A A C$ ] e a observação da flora e fauna local (AAAC, 2009).

\section{Análise dos Discursos}

Os discursos midiáticos relacionados ao modelo agroturístico apresentam-se sob o formato de uma rede de informações que se intercruzam, formando elos entre os diversos pontos que se justificam exatamente por existirem atreladas umas as outras. De outro modo podemos dizer que os elementos que formam os discursos agem seqüencialmente, com um fator a gerar estímulo para o aparecimento do fator seguinte, e assim por diante até voltar ao ponto inicial. A dimensão final é a criação de uma cadeia de dependência entre todos os pontos, ligados a um ponto central que é o agroturismo (CUNHA LIMA; OLIVEIRA; SILVA, 2008).

No que se refere aos discursos acadêmicos, percebe-se que a maioria tem como "referência ou ancoragem base" Guzzatti (2003), por ter sido o primeiro trabalho a sistematizar todo o processo que deu origem ao modelo agroturístico em questão. Outra característica marcante é a presença da agroecologia nos discursos, o que se justifica pelo fato desses dois projetos caminharem entrelaçados. As questões mais freqüentes relacionam-se as mudanças no cotidiano da população e da cidade, a criação de novos hábitos, modificações físicas, e os riscos e benefícios gerados pelo turismo.

A valorização das características locais é o primeiro tema em comum entre a mídia e a academia: ambas ressaltam que os aspectos naturais e culturais são os principais atrativos. Destacando a construção de novos hábitos e/ou à adaptação de hábitos antigos, temos: a interação entre visitantes e 
visitados resultando em uma troca de experiências em um ambiente confiável e alegre, um maior contato com a natureza e uma gastronomia a base de produtos orgânicos. Uller (2005) e Heuser (2002) são alguns dos acadêmicos que enfatizam esta questão em suas pesquisas; já na mídia podemos mencionar o Diário Catarinense (2007) e a Revista Globo Rural (2007).

Isso é um reflexo do modelo implantado, no qual os agricultores passaram por todo um processo de formação, adquirindo conhecimentos sobre esta nova atividade, participando de grupos de estudo, seminário e intercâmbios. O fator educativo dentro deste contexto é tão marcante que transcende o território da comunidade, sendo destacado em trabalhos acadêmicos e alcançando inclusive a mídia, caracterizando o segundo ponto de convergência entre esses dois meios. Tais ações conferem credibilidade ao projeto de agroturismo, além de melhorar a imagem da atividade perante a sociedade como um todo, como observado por Heuser (2002) e pelo jornal Folha do Vale (2007).

Em se tratando dos pontos divergentes, observamos que a mídia não percebe que a geração de emprego e renda, a melhoria da qualidade de vida e a preocupação com as questões ambientais são conseqüências esperadas com a implantação do modelo, pois relacionam esses fatores a uma resposta mercadológica, como apresentado pela Revista Globo Rural (2007), enquanto que na academia essas conseqüências são vistas como objetivos a serem alcançados (ULLER, 2005; GUZATTI, 2003).

Sob essa ótica, os meios de comunicação passam a divulgar o exemplo de Santa Rosa de Lima como modelo de sucesso, atrelando-o muito mais as conseqüências econômicas resultantes da atividade. Sobre a filosofia do associativismo e cooperativismo que prima pela participação do agricultor, apenas a Revista Brasil Almanaque de Cultura Popular (2008) a enfatizou como um aspecto positivo de todo o processo. Nesse sentido, a academia, diferente da mídia, busca sempre destacar o modelo de gestão solidária com seus princípios e normas, deixando em segundo plano o lado mercantilista da atividade turística (SILVA; FEUSER, 2007). 
Exatamente por ter como objetivo principal a inserção de um produto no mercado, a mídia não aborda as questões relativas às fragilidades da atividade, já que estas prejudicam a imagem do destino, o que pode acarretar na diminuição do fluxo turístico. Diferentemente, a academia tem interesse em divulgar este tipo de informação para que se possam encontrar soluções para as mesmas.

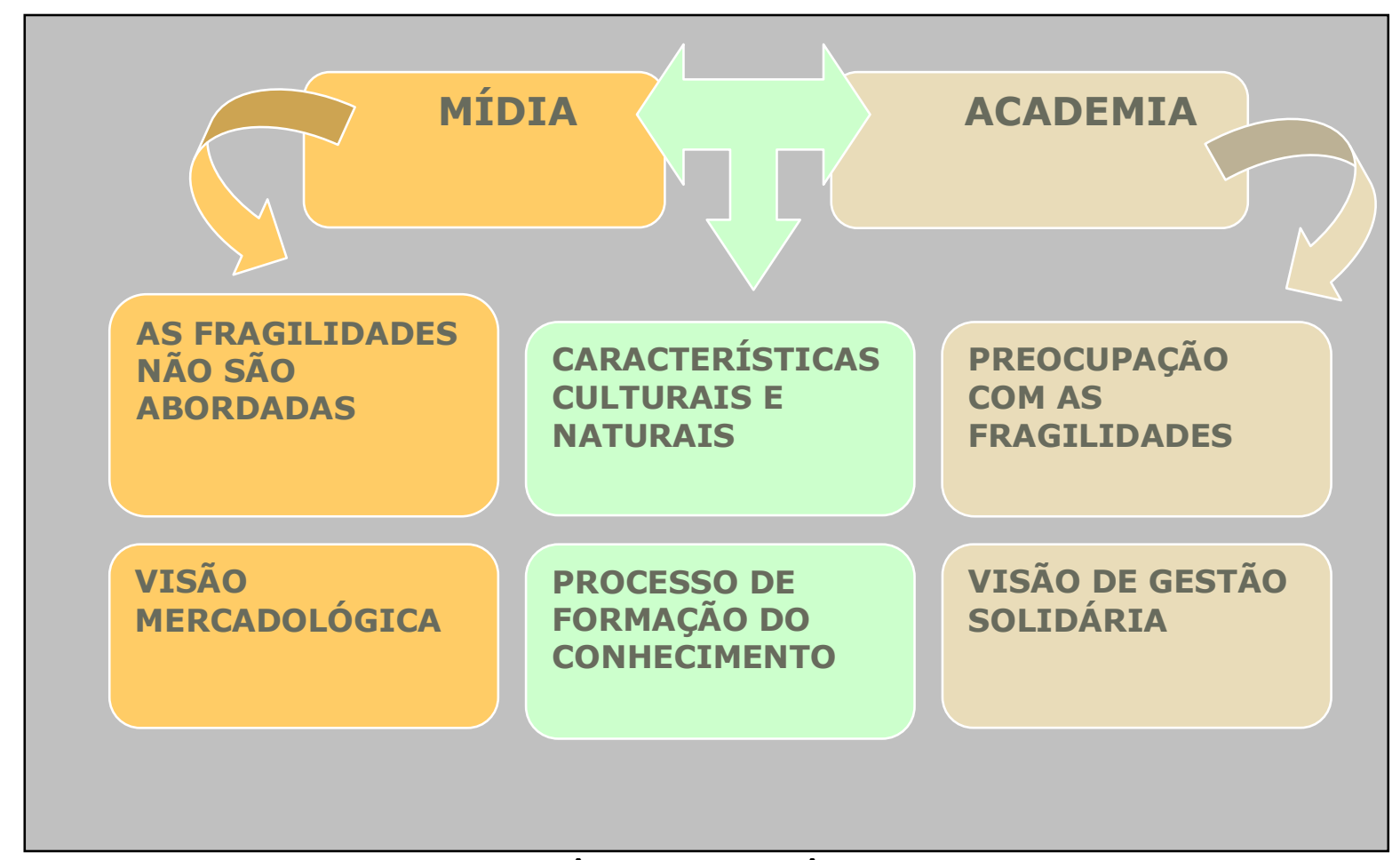

Figura 1 - Convergências e divergências e dos discursos

Fonte: os autores (2009)

\section{Considerações Finais}

Traçar um perfil das semelhanças e diferenças apresentadas entre os discursos midiáticos e acadêmicos revelou fatores que favorecem o entendimento da realidade de Santa Rosa de Lima, embora essa diversidade de olhares também gere desvios de percepção, uma vez que cada ator envolvido avalia o modelo a partir de seu referencial. Desta forma, um mesmo fato pode assumir um caráter positivo, negativo ou até mesmo nada significar para quem apenas observa. 
A questão da mulher no agroturismo é um exemplo de desvio, por ser um discurso que possui três interpretações: a academia aponta para a sobrecarga da mesma em função do acumulo de tarefas; já a mulher percebe tal discurso como uma valorização pessoal, ao assumir novos papéis que Ihe renderam maior destaque na sociedade local; e por sua vez a mídia é neutra e nem mesmo questiona esse fato.

Os desvios são criados tanto na construção como na divulgação da informação/conhecimento. Dessa forma percebemos que existem nuanças de entendimento dentro dos próprios grupos fazendo com que a própria percepção dos desvios seja relativa. A verificação e divulgação da existência de desvios são de fundamental importância, pois estes podem interferir direta ou indiretamente na gestão da atividade.

Acreditamos que a ocorrência de desvios poderia ser menor se a academia tivesse um compromisso maior com a comunidade pesquisada, devolvendo a esta os resultados de seus estudos. Sugerimos então algumas diretrizes para a socialização destes conhecimentos: (1) a criação de um termo de compromisso entre o pesquisado e o pesquisador, no qual o último assume a responsabilidade quanto a devolução dos resultados da pesquisa; (2) a realização de um evento para a apresentação dos trabalhos científicos; (3) e a criação de um banco de dados dos estudos acadêmicos e demais assuntos relacionados a atividade.

Acreditamos que a realização dessas diretrizes vai possibilitar que a população local tenha acesso as informações, e estas podem colaborar para o melhor entendimento de sua realidade, assim como para a solução de seus problemas. O que indubitavelmente refletiria em discursos midiáticos mais condizentes com a realidade e menos superficiais, pois os envolvidos no processo teriam melhores condições de dimensionar e direcionar a imagem que desejam transmitir.

\section{Referências}


ALBANESE, M. Sinta-se em Casa. Brasil Almanaque de Cultura Popular. Tam Editorial, São Paulo, n.114, p.11, out, 2008.

BEAUD, S.; WEBER, F. Guia para a pesquisa de campo: produzir e analisar dados etnográficos. Petrópolis: Vozes, 2007.

BERGEER, P.; LUCKMANN, T. A construção social da realidade: tratado de sociologia do conhecimento. 17.ed. Petrópolis: Vozes, 1985.

BOURDIEU, P. O poder simbólico. 5.ed. Rio de Janeiro: Bertrand Brasil, 2002.

CUNHA LIMA, F. B. O agroturismo em Santa Rosa de Lima - SC: um estudo dos discursos midiáticos e suas influências na gestão da atividade. 2009. 155f. Dissertação (Programa de Mestrado Acadêmico em Turismo e Hotelaria). Universidade do Vale do Itajaí, Balneário Camboriú, 2009.

CUNHA LIMA, F. B; OLIVEIRA, L. S; SILVA, Y. F. Análise do discurso midiático do projeto "Acolhida na Colônia" na atividade do agroturismo em Santa Rosa de Lima - SC. In: SEMINÁRIO INTERNACIONAL DE TURISMO, 10, 2008, Curitiba. Publicação da comunicação em actas (CD-ROM). 2008.

DURKHEIM, E. As regras do método sociológico. In: DURKHEIM. Os Pensadores. 2.ed. São Paulo: Abril Cultural, 1983.

ECO, U. Lector in fabula. São Paulo: Perspectivas, 1986.

FEUSER, L. O Agroturismo em Santa Rosa de Lima: itinerários da formação de turismo sustentável nas Encostas da Serra Geral. 2006. 96f. (Monografia) Curso de Turismo e Hotelaria. Centro de Educação. Universidade do Vale do Itajaí, Balneário Camboriú, 2006.

GADINI, S. L. A produção da cultura no jornalismo contemporâneo: considerações sobre o discurso da informação na construção da identidade. XXII Congresso Brasileiro de Ciências da Comunicação/Congresso da Intercom, Rio de Janeiro. Publicação da comunicação em actas (CD-ROM). 1999.

GUZZATTI, T. C. O agroturismo como instrumento de desenvolvimento rural: sistematização e análise das estratégias utilizadas para a implantação de um programa de agroturismo nas Encostas da Serra Geral Catarinense. 2003. 168f. Dissertação. (Programa de Pós Graduação em Engenharia de Produção). Universidade Federal de Santa Catarina. Florianópolis, 2003.

HEUSER, D. M. D. Repercussão do agroturismo na qualidade de vida dos núcleos familiares receptores de Santa Rosa de Lima (SC): um processo criativo e solidário. 2002. 127f. Dissertação. (Programa de Pós Graduação em Engenharia de Produção). Universidade Federal de Santa Catarina. Florianópolis, 2002.

Hospitalidade na Capital da Agroecologia. Diário Catarinense, Florianópolis, 09 de nov., 2007. Caderno Especial o Melhor de Santa Catarina, p. 57.

KISS, J. Porteiras Abertas. Globo Rural. Editora Abril, São Paulo, n.259, p. 4253, mai., 2007.

LEFEVRE, F.; LEFEVRE A. M. C. O discurso do sujeito coletivo: um novo enfoque em pesquisa qualitativa (desdobramentos). Caxias do Sul: EDUCS, 2003.

MONTIEL, E. A nova ordem simbólica: a diversidade cultural na era da globalização. In: SIDEKUM, A. Alteridade e multiculturalismo. Ijuí: Unijuí, 2003. 
OLIVEIRA, L. S. Agroturismo em Santa Rosa de Lima - SC: os discursos sobre o modelo implantado e a socialização do 'saber' nas produções construídas de 2002-2007. 2009. 115f. Dissertação (Programa de Mestrado Acadêmico em Turismo e Hotelaria). Universidade do Vale do Itajaí, Balneário Camboriú, 2009.

Programa Qualifica Condutores de Santa Rosa para Turismo de Aventura. Folha do Vale. Braço do Norte. 25 jun. 2007. Disponível em: http://www.folhadovale.com.br/principal.php?pag =coluna\&cod $=1317 \& b s c=1 \& t$ $\mathrm{p}=2$

SANTOS, R. J. Antropologia pra quem não vai ser antropólogo. Porto Alegre: Tomo Editorial, 2005.

SILVA, Y. F. Cuidando de si ou violência corporal? O discurso sobre o envelhecimento na mídia. Florianópolis, 1999. 220 f. Tese (Doutorado em Filosofia da Saúde) - Centro de Ciências da Saúde/Programa de PósGraduação em Enfermagem, Universidade Federal de Santa Catarina.

SILVA, Y. F.; FEUSER, L.O. O agroturismo em Santa Rosa de Lima: itinerários da formação sustentável nas encostas da serra geral. In: Encontro Nacional de Turismo com Base Local, 10. João Pessoa. Anais. João Pessoa: ENTBL, 2007. p. 573-581.

ULLER, C, D. O agroturismo de Santa Rosa de Lima - SC: características e singularidades da hospedagem familiar. 2005. 131f. Dissertação. (Programa de Pós Graduação Strictu Sensu em Turismo e Hotelaria). Universidade do Vale do Itajaí, Balneário Camboriú, 2005.

Artigo recebido em agosto de 2010.

Aprovado para publicação em novembro de 2010. 